\title{
Investigating Water Permeation through the Soil-Rock Mixture in Underground Engineering
}

\author{
Yingchao Wang',2*, Fanshu Meng², Fan Geng ${ }^{3}$, Hongwen Jing', Ning Zhao \\ ${ }^{1}$ State Key Laboratory for Geomechanics and Deep Underground Engineering, China University of Mining \\ and Technology, Xuzhou, Jiangsu 221116, China \\ ${ }^{2}$ School of Mechanics and Civil Engineering, China University of Mining and Technology, \\ Xuzhou, Jiangsu 221116, China \\ ${ }^{3}$ School of Electrical and Power Engineering, China University of Mining and Technology, \\ Xuzhou, Jiangsu 221116, China
}

Received: 28 October 2016

Accepted: 23 February 2017

\begin{abstract}
Groundwater inrush within faults is an important issue in underground engineering. The process of water permeation through the soil-rock mixture has been numerically investigated. The simulated soil-rock mixture was presented with rock blocks, and filled with selected types of soil particles. The Euler-Euler method was employed with multiphase interaction. Meanwhile, the filling soil was assumed to be Bingham fluid with additional user-defined function. Then the detailed evolutions of water permeation through the soil-rock mixture were presented visually, including water distribution, water velocity field, permeation time, and penetration time. It is shown that water permeation changes with time and space in the soil-rock mixture, and the overall process of water permeation can be divided into three different stages. Moreover, major variables including water velocity, size of soil particles, and yield stress of soil were considered, which clearly influenced water permeation. Soil density showed little effect on water permeation, and the permeation time decreases with increasing water velocity. Water permeation through the soil-rock mixture is easier when the filling soil consists of smaller particles. The permeation rate of water obviously decreases with increasing yield stress. Meanwhile, different types of soils were considered with corrections on the dynamic viscosities. We found that sand and soil behave differently when water permeates through the soilrock mixture. Furthermore, selected results on water permeation were compared with the relevant studies, and reasonable agreements were reached. The presented stimulation results provide detailed information for further understanding on the mechanical mechanism of water permeation through the soil-rock mixture used in underground engineering.
\end{abstract}

Keywords: water permeation, soil-rock mixture, water distribution, Bingham fluid, Euler-Euler method

*e-mail: wych12345678@126.com 


\section{Introduction}

Water inrush has become the most serious problem for underground engineering. Recently, a large number of studies have been devoted to this problem for tunnel construction and mining, but it remains very difficult to understand water inrush. Thus, further research on water inrush is essential and urgent [1-3]. Based on the disasterinduced geological structures, water inrush can be induced by multiple factors, including groundwater [4-5], fractured rocks [6-7], fluid permeation into the filling materials of rocks, and the cooperation of the above factors [8-9]. Meanwhile, inrush accidents induced by groundwater in Chinese mines have caused the deaths of several hundred miners each year this century [4].

The research of water inrush has been popular in recent years. For one thing, various methods proposed originally or derived from other fields have been used to evaluate the risk of water inrush in tunnels [10-18]. Many new models have been presented and successfully applied in many other fields, such as forecasting the monthly inflow of Dez Dam Reservoir [19], variations of land use [20], evapotranspiration to increase the accuracy of the estimations [21], and rainfall estimation [22]. For another thing, more and more attention has been paid to the mechanism of groundwater inrush, while the relevant research mainly focuses on the reaction of faults and the damage of floor strata as far as we know [4, 23-24]. Particularly, potential influences have been mainly overlooked in previous research on the faults, including the configurational structure of particles within the fractured rocks $[4,25]$. A number of researchers have gained useful findings on particle rearrangements within a granular setting and have reported strong permeability variation [26-27]. It is still significant to consider the hydraulic properties of granular rocks within fault rocks [4].

Fractured rocks are essential, in addition to soil, for creating a typical mixture of soil and rock. Soil and rock mixtures are not only a common geotechnical material in nature, but also a typical geotechnical material often encountered in various engineering construction projects [28]. Soil-rock mixture (S-RM) is an extremely heterogeneous and loose geotechnical material that can be formed during the construction of underground engineering. It consists of high-strength rock blocks with large size, fine soil particles, and pores [28-30]. The mesostructural characteristics of S-RM not only induce its deformation, but also lead to the failure mechanism during the construction of underground engineering. Many efforts have been devoted to study soil and rock mixtures [31-32]. For example, during tunnel construction, S-RM is affected by multiple factors from the surrounding environment, including water resources, water permeation, seepage instability, geological structure, and other activities [3334]. Meanwhile, water permeation is essential to seepage instability. The microcosmic seepage flow leads directly to macroscopic water inrush [35]. Water permeation and particle migration in the geotechnical mixture is a key issue to further understand the mechanism of water inrush disaster. Thus, studies focusing on the mechanical behavior of S-RM with water permeation are very important for understanding the stability evolution of this kind of geotechnical material for groundwater inrush disaster.

Numerous methods have been presented to gain a better understanding of these kinds of geotechnical materials, including physical model testing, numerical analysis, and experimental investigation. However, it is difficult to carry out field or laboratory tests at full scale. Moreover, it is difficult to carry out direct field measurements on permeability evolution of granular rocks deep underground [4]. Fortunately, numerical methods have great advantages for the study of S-RM under complicated conditions. Numerical investigations have been approved as a feasible means of disclosing complex phenomena. Vallejo investigated the behavior of granular materials containing large particles based on laboratory and finite element methods [36]. Yue et al. developed a DIP technique to establish the actual microstructures of geomaterials, which is called the DIP-based finite element method [37-38]. Li et al. [39] explored numerical analysis to investigate the deformation and failure modes of weak rock mass surrounding a tunnel. Xu et al. [40] used the discrete element method to study the mechanical behavior of soil-rock mixtures (S-RM) in a landslide dam. The numerical studies have gained useful understanding on the mechanical behavior of water permeation within S-RM, while the relevant research on the two-phase flow of water and the filling particles are rare, which is still complex to know fully.

In this work, water permeation through the soil-rock mixture was numerically studied to further understand the mechanical behaviors of groundwater inrush. First, selected samples of soil-rock mixtures were presented with random rock blocks and different soil particles. The structural configuration of soil particles within the fractured rocks was considered, and different types of soil particles were presented in respect to sand and soil. Second, the water influence on the mixture was considered in three phases, including soil particles between rock blocks, air in pores, and water action. For the three-phase system, the Euler-Euler method was applied. The filling soil was assumed to be a type of non-Newtonian fluid using the Bingham model, and the user-defined functions on the dynamic viscosities of different soils were used. The processes of water permeation through the soilrock mixture were numerically studied for selected soil models. Third, the detailed evolutions of water permeation and particle migration were presented visually. The flow behavior of water permeation and particle migration were analyzed in detail. Moreover, water velocity, size of soil particles, yield stress of soil, and soil density were considered for their influence on water behavior. Finally, selected simulation results were compared with the relative research results to validate established models, and reasonable agreements will be shown. 


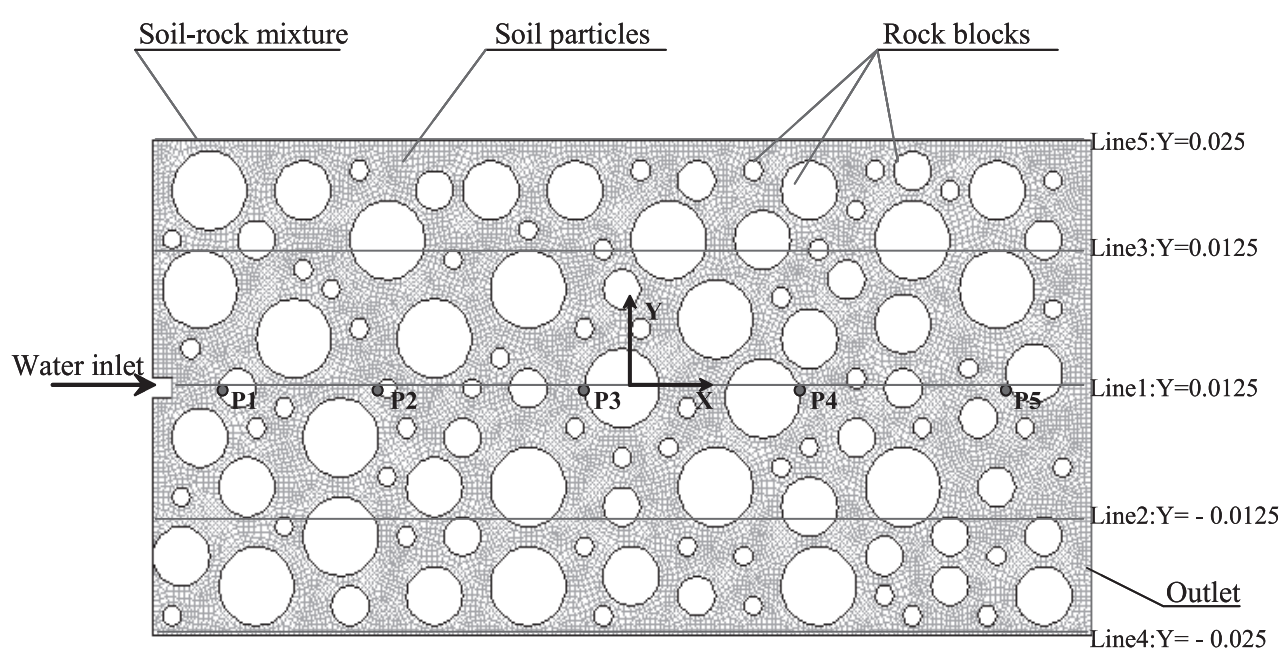

Fig. 1. Structure of the simulated soil-rock mixture.

\section{Mathematical Method}

The simulated model of soil-rock mixture was based on the previous experimental research $[32,34,40]$, as shown in Fig. 1. A unit of soil-rock mixture was investigated with random fixed rock blocks. The skeleton was filled with permeable materials, such as granular soils. Granular soils were selected as the filling material. Thus, the soilrock mixture was filled with granular soils between rock blocks and certain air in the interval between the soil particles. On the left-hand side, there was a water inlet with a given hydraulic pressure. On the right-hand side, the outlet was exposed to the atmospheric environment. Water generates pressure on the mixture. Then water permeates into the granular soil. The filling soil becomes loose and gradually flows away under the action of water. Thus, water can transfer through the mixture, and finally releases into the atmospheric environment. The process of water permeation through the soil-rock mixture is relevant with the water phase, solid phase of granular soil, and the air phase. It has a typical flow of air-water-soil in three phases. In this work, the process of water permeation through the soil-rock mixture was numerically simulated with the Euler-Euler model.

The Euler-Euler model was adopted based on the following assumptions:

A) The heat and mass transfer are ignored in the flow process.

B) Normal water was used as the operational fluid, which is defined as the continuous phase. The existence of normal air and other gases is considered.

C) The filling soils are treated as the spherical continuous phase with consideration of the large amount of soil particles. The soil was also considered with certain sizes of soil particles and different dynamic viscosities.

\section{Euler-Euler Model}

Water migration through the soil-rock mixture is usually accompanied by air, which unavoidably exists within the interval of the skeleton. The simulation on water permeation through the soil-rock mixture is based on the approach of multiphase flow. Water and air are assumed to be continuous and fully interpenetrating in each control volume, while the solid phase of soil is defined as a special kind of fluid, namely Bingham fluid. The conservative equations of mass and momentum originally derived from single-phase flow can be extended to describe the hydrodynamics of the three-phase flow [41-43].

\section{Volume Fractions}

The two-phase flow was described as an interpenetrating continua, and volume fractions $\alpha_{q}$ were introduced to represent the space occupied by each phase [44-45].

The volume of phase $q, V_{q}$, is defined by:

$$
V_{q}=\int_{V} \alpha_{q} d V
$$

...where $\sum_{q=1}^{n} \alpha_{q}=1$. The effective density of phase $q$ is $\hat{\rho}_{q}=\alpha_{q} \rho_{q}$, where $\rho_{q}$ is the physical density of phase $q$.

The conservation laws of mass and momentum are separately satisfied by each of the two phases, which are described as follows.

\section{Conservation of Mass}

The continuity equation for phase $q$ is:

$$
\frac{\partial}{\partial t}\left(\alpha_{q} \rho_{q}\right)+\nabla \cdot\left(\alpha_{q} \rho_{q} v_{q}\right)=\sum_{p=1}^{n} m_{p q}+S_{q}
$$

...where $\stackrel{V_{q}}{V_{q}}$ is the velocity of phase $q$ and $m_{p q}$ characterizes the mass transfer from the $p$ to $q$ phase, and these mechanisms can be specified separately. The source term $S_{q}$ on the right-hand side is zero. 


\section{Conservation of Momentum}

The momentum balance for phase $q$ yields:

$\frac{\partial}{\partial t}\left(\alpha_{q} \rho_{q} v_{q}\right)+\nabla \cdot\left(\alpha_{q} \rho_{q} v_{q} v_{q}\right)=-\alpha_{q} \nabla p+\nabla \cdot \overline{\overline{\tau_{q}}}+$

$+\sum_{p=1}^{n}\left(\stackrel{V}{R}_{p q}+m_{p q} \stackrel{V}{v_{p q}}\right)+\alpha_{q} \rho_{q}\left(\stackrel{V}{F}_{q}+\stackrel{V}{F}_{\text {lift }, q}+\stackrel{V}{F}_{V m, q}\right)$

...where $\overline{\overline{\tau_{q}}}$ is the $q$ phase stress-strain tensor.

$$
\bar{\tau}=\alpha_{q} \mu_{q}\left(\nabla v_{q}+\nabla v_{q}^{T}\right)+\alpha_{q}\left(\lambda_{q}-\frac{2}{3} \mu_{q}\right) \nabla \cdot v_{q} \overline{\bar{I}}
$$

...where $\mu_{q}$ and $\lambda_{q}$ are the shear and bulk viscosity of phase $q, \underset{\mathbf{v}}{F_{q}}$ is an external body force, $F_{\text {lift, } q}$ is a lift force, $F_{V m, q}$ is a virtual mass force, $R_{p q}$ is an interaction force between phases, and $p$ is the pressure shared by all phases. $v_{p q}$ is the interphase velocity, defined as follows. If $m_{p q}>0$ (i.e., phase $p$ mass is being transferred to phase $p$ ), $v_{p q}=v_{q}$; if $m_{p q}>0$ (i.e., phase $q$ mass is being tran$\underset{\mathrm{V}}{\text { fferred to phase }} p), \mathbf{v}_{p q}=\mathbf{v}_{q}$. Likewise, if $m_{p q}>0$ then $\stackrel{\mathrm{v}}{v}_{p q}=\stackrel{\mathrm{v}}{v}_{q}$, if $m_{p q}>0$ then $v_{p q}=\stackrel{\mathrm{V}}{v_{p}}$.

Equation (3) must be closed with appropriate expressions for the interphase force $\stackrel{\mathrm{V}}{R_{p q}}$. This force depends on friction, pressure, cohesion, and other effects, and is subject to the conditions that $\stackrel{\mathrm{v}}{R}_{p q}=-\stackrel{\mathrm{v}}{R p}_{q}$ and $\stackrel{\mathrm{v}}{R}_{p q}=0$.

A simple interaction term of the following form has been used:

$$
\sum_{p=1}^{n} R_{p q}=\sum_{p=1}^{n} K_{p q}\left(v_{p}-v_{q}\right)
$$

$\ldots$ where $K_{p q}\left(=K_{q p}\right)$ is the interphase momentum exchange coefficient.

\section{Turbulence in the Continuous Phase}

The eddy viscosity model is used to calculate average fluctuating quantities. The Reynolds stress tensor for continuous phase $q$ takes the following form:

$$
\overline{\bar{\tau}}^{\prime \prime}=-\frac{2}{3}\left(\rho_{q} k_{q}+\rho_{q} \mu_{t, q} \nabla \cdot U_{q}\right) \overline{\bar{I}}+\rho_{q} \mu_{t, q}\left(\nabla U_{q}+\nabla U_{q}^{T}\right)
$$

...where $U_{q}^{\mathrm{v}}$ is the phase-weighted velocity.
The turbulent viscosity $\mu_{t, q}$ is written in terms of the turbulent kinetic energy of phase $q$ :

$$
\mu_{t, q}=\rho_{q} C_{\mu} \frac{k_{q}^{2}}{\varepsilon_{q}}
$$

... and a characteristic time of the energetic turbulent eddies is defined as:

$$
\tau_{t, q}=\frac{3}{2} C_{\mu} \frac{k_{q}}{\varepsilon_{q}}
$$

$\ldots$ where $\varepsilon_{q}$ is the dissipation rate and $C_{\mu}=0.09$.

The length scale of the turbulent eddies is:

$$
L_{t, q}=\sqrt{\frac{3}{2}} C_{\mu} \frac{k_{q}^{\frac{3}{2}}}{\varepsilon_{q}}
$$

Turbulent predictions are obtained from the modified $k-\varepsilon$ model:

$$
\begin{gathered}
\frac{\partial}{\partial t}\left(\alpha_{q} \rho_{q} k_{q}\right)+\nabla \cdot\left(\alpha_{q} \rho_{q} \stackrel{\mathrm{v}}{U_{q}} k_{q}\right)=\nabla \cdot\left(\alpha_{q} \frac{\mu_{t, q}}{\sigma_{k}} \nabla k_{q}\right)+\alpha \\
+\alpha_{q} G_{k, q}-\alpha_{q} \rho_{q} \varepsilon_{q}+\alpha_{q} \rho_{q} \prod_{k_{q}}
\end{gathered}
$$

and

$$
\begin{gathered}
\frac{\partial}{\partial t}\left(\alpha_{q} \rho_{q} \varepsilon_{q}\right)+\nabla \cdot\left(\alpha_{q} \rho_{q} \stackrel{\mathrm{V}}{U_{q}} \varepsilon_{q}\right)=\nabla \cdot\left(\alpha_{q} \frac{\mu_{t, q}}{\sigma_{\varepsilon}} \nabla \varepsilon_{q}\right)+\alpha_{1} \\
+\alpha_{q} \frac{\varepsilon_{q}}{k_{q}}\left(C_{1 \varepsilon} G_{k, q}-C_{2 \varepsilon} \rho_{q} \varepsilon_{q}\right)+\alpha_{q} \rho_{q} \Pi_{\varepsilon_{q}}
\end{gathered}
$$

...where $\Pi_{k}$ and $\Pi_{\varepsilon}$ represent the influence of the dispersed phases on the continuous phase $q$, and $G_{k, q}$ is the production of turbulent kinetic energy. All other terms have the same meaning as in the single-phase $k-\varepsilon$ model.

\section{Dispersed Model for k-epsilon Multiphase}

When the concentration of the second phase is relatively small, it is necessary to select the dispersed model from k-epsilon multiphase models. Though particle contact is ignored and the leading function on the second phase primarily comes from the main phase, the action of the second phase can be determined by the balance feature of the main phase, the relaxation time, and the interacting time of particles. Furthermore, dispersion coefficients, correlation functions, and the turbulent kinetic energy of 
each dispersed phase are evaluated with time and length scales, which could characterize the motion.

The characteristic particle relaxation time connected with inertial effects acting on a dispersed phase $p$ is defined as:

$$
\tau_{F, p q}=\alpha_{p} \rho_{p} K_{p q}^{-1}\left(\frac{\rho_{p}}{\rho_{q}}+C_{V}\right)
$$

The Lagrangian integral time scale calculated along particle trajectories, mainly affected by the crossingtrajectory effect, is defined as:

$$
\tau_{t, p q}=\frac{\tau_{t, q}}{\sqrt{\left(1+C_{\beta} \xi^{2}\right)}}
$$

... where

$$
\begin{gathered}
\xi=\frac{\left|v_{p q}\right| \tau_{t, q}}{L_{t, q}} \\
C_{\beta}=1.8-1.35 \cos ^{2} \theta
\end{gathered}
$$

...where $\theta$ is the angle between the mean particle velocity and the mean relative velocity. The ratio between these two characteristic times is written as:

$$
\eta_{p q}=\frac{\tau_{t, p q}}{\tau_{F, p q}}
$$

Following Simon in Cooper et al., 2005, the turbulence quantities for dispersed phase $p$ can be calculated as follows:

$$
\begin{gathered}
k_{p}=k_{q}\left(\frac{b^{2}+\eta_{p q}}{1+\eta_{p q}}\right) \\
k_{p q}=2 k_{q}\left(\frac{b+\eta_{p q}}{1+\eta_{p q}}\right) \\
D_{t, p q}=\frac{1}{3} k_{p q} \tau_{t, p q} \\
D_{p} D_{t, p q}+\left(\frac{2}{3} k_{p}-b \frac{1}{3} k_{p q}\right) \tau_{F, p q} \\
b=\left(1+C_{V}\right)\left(\frac{\rho_{p}}{\rho_{q}}+C_{V}\right)^{-1}
\end{gathered}
$$

and $C_{V}=0.5$ is the added-mass coefficient.

\section{Interphase Turbulent Momentum Transfer}

The turbulent drag term for multiphase flows ( $K_{p q}\left(\mathfrak{v}_{p}-v_{q}\right)$ in Eq. 5) is modeled as follows, for dispersed phase $p$ and continuous phase $q$ :

$$
K_{p q}\left(v_{p}-v_{q}\right)=K_{p q}\left(U_{p}-U_{q}\right)-K_{p q} v_{d r}
$$

The second term on the right-hand side of Eq. 22 contains the drift velocity:

$$
v_{d r}=-\left(\frac{D_{p}}{\sigma_{p q} \alpha_{p}} \nabla \alpha_{p}-\frac{D_{q}}{\sigma_{p q} \alpha_{q}} \nabla \alpha_{q}\right)
$$

...where $D_{p}$ and $D_{q}$ are diffusivities, and $\sigma_{p q}$ is a dispersion Prandtl number. When using Tchen theory in multiphase flows, it assumes $D_{p}=D_{q}=D_{t, p q}$ and the default value for $\sigma_{p q}$ is 0.75 .

\section{Interaction between Fluid-Solid}

For the interaction between fluid-solid, the drag function is considered. Drag coefficient is of crucial importance for the simulation of the heterogeneous gassolid flow [44-45]. And the Schiller and Naumann model is selected as the default method, which is acceptable for general use in all fluid-fluid multiphase calculations.

\section{User-Defined Function on Dynamic Viscosity}

Common fluids, like air and water, are Newtonian fluids. This indicates that the viscous behaviors for Newtonian fluids should obey Stokes' law of viscosity. In detail, viscosity is defined as the ratio of shear stress versus shear rate, which is regarded as constant for Newtonian fluids. In contrast, there also exist some fluids that do not obey Stokes' law, namely non-Newtonian fluids. For example, many geological and industry materials belong to non-Newtonian fluids, such as clay, mud, ice, lava, and so forth.

With the consideration of the characteristics of geological materials, special soils were used to fill the soilrock mixture. Meanwhile, the filling soil was assumed as a non-Newtonian fluid. The Bingham model was applied for the dynamic viscosity of soil, since several examples belong to Bingham fluids, including clay suspensions, drilling mud, toothpaste, mayonnaise, chocolate, and mustard. According to Bingham relation [46-47], fluids that have a linear shear stress/shear strain relationship require a finite yield stress before they begin to flow. For Bingham fluids, the shear stress $\overline{\bar{\tau}}$ can be described as:

$$
\overline{\bar{\tau}}=\overline{\overline{\tau_{0}}}+\eta_{\mathrm{p}} \overline{\bar{D}}
$$


Table 1. Physical and numerical parameters used in the model.

\begin{tabular}{|c|c|}
\hline Properties & Value \\
\hline $\begin{array}{c}\text { Size of simulated soil-rock mixture } \\
(\mathrm{m})\end{array}$ & $0.1 \times 0.05$ \\
\hline Diameter of the water inlet $(\mathrm{m})$ & 0.02 \\
\hline Diameter of soil particles $(\mu \mathrm{m})$ & $100,10,1,0.01$ \\
\hline Soil density $\left(\mathrm{kg} / \mathrm{m}^{3}\right)$ & $1,100,1,600,2,650$ \\
\hline Yield stress of soil $(\mathrm{Pa})$ & $1,10,50,100$ \\
\hline $\begin{array}{c}\text { Non-Newtonian viscosity of soil } \\
\left(\mathrm{m}^{2} / \mathrm{s}\right)\end{array}$ & 0.1 \\
\hline Water density $\left(\mathrm{kg} / \mathrm{m}^{3}\right)$ & 998.2 \\
\hline Water viscosity $\left(\mathrm{m}^{2} / \mathrm{s}\right)$ & $1.003 \times 10^{-3}$ \\
\hline Water velocity $(\mathrm{m} / \mathrm{s})$ & $0.5,1,2,5$ \\
\hline Air density $\left(\mathrm{kg} / \mathrm{m}^{3}\right)$ & 1.225 \\
\hline Air viscosity $\left(\mathrm{m}^{2} / \mathrm{s}\right)$ & $1.7894 \times 10^{-5}$ \\
\hline
\end{tabular}$$
=
$$ \\ ...where $\overline{\overline{\tau_{0}}}$ is yield stress, $\eta_{p}$ is non-Newtonian viscosity, \\ and $\overline{\bar{D}}$ is the rate-of-deformation tensor.
}

\section{Simulation Conditions}

The numerical solution of the established model for the air-water-solid three phases were based on the Euler-Euler model of computational fluid dynamics platform. The user-defined function on dynamic viscosity of soil phase was presented with the Visual $\mathrm{C}++$ codes. The physical properties of the system are given in Table 1 .

\section{Results and Discussion}

\section{Water Permeation in the Soil-Rock Mixture}

To observe migration in the soil-rock mixture, numerical simulations were performed to grasp water distribution regularity. After a series of simulations, snapshots of water distribution at various time points are presented, as shown in Fig. 2. The initial water velocity is $1 \mathrm{~m} / \mathrm{s}$, and the diameter of soil particles is $100 \mu \mathrm{m}$.

As shown in Fig. 2, the soil-rock mixture is full of soil particles with air in the interval between the soil particles at the beginning. Water permeates into the soilrock mixture under certain pressure at the inlet. Water easily diffuses all around by replacing the air in intervals. Meanwhile, the soil particles are carried away by water, mainly moved forward, and discharged from the mixture, leaving space for additional water. Water quickly occupies the transverse direction and moves forward along the soil-rock mixture accompanied by the removal of soil particles. Water permeation will change its direction when it meets fixed particles and walls, and it continues until it reaches the outlet. During the permeation process, the

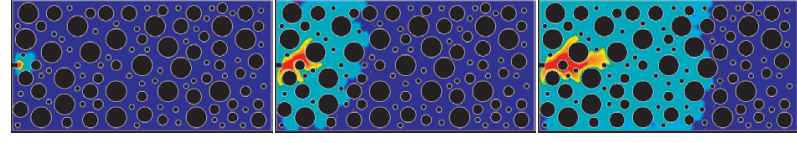

$\mathrm{t}=0.002 \mathrm{~s}$

$\mathrm{t}=0.4 \mathrm{~s}$

$\mathrm{t}=1.0 \mathrm{~s}$

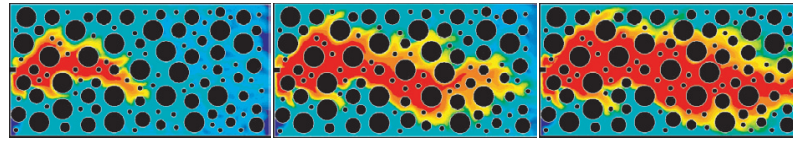

$\mathrm{t}=2.0 \mathrm{~s}$

$\mathrm{t}=2.5 \mathrm{~s}$

$\mathrm{t}=3.0$

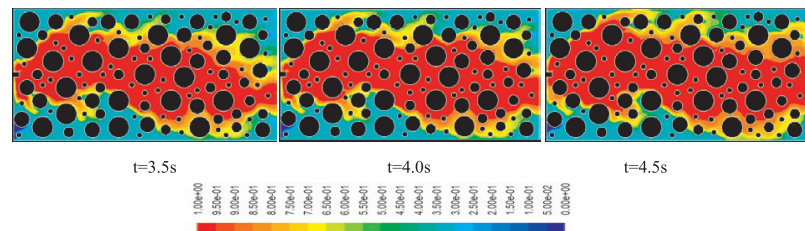

Fig. 2. Snapshots of water permeation through the soil-rock mixture at various times.

flow channel of water forms gradually. The channel flow follows the permeation, and slowly extends along the soilrock mixture. When water permeation passes through the soil-rock mixture, the channel flow of water quickly moves forward and discharges from the outlet. Thus, water penetration forms with continued particle migration. The quantity of particles discharged out of the mixture increases during the permeability evolution. As time goes by, the flow channel of water also extends in the transverse direction, which finally forms a plug flow. Water flows out, leaving the porous, unstable skeleton, which might induce water inrush through fractured rocks.

In brief, the overall process of water permeation during the numerical tests can be divided into three different stages: first, water was injected into the soil-rock mixture and the filling particles were forced to adjust; second, water permeation develops gradually, accompanied by limited particle migration; third, water penetrates thorough the mixture with continued moderate particle migration and steady-state water flow. The three different stages of the permeability evolution coincide with the relevant experimental results [4].

Water penetration forms and mainly follows a selected way along the soil-rock mixture, as shown in Fig. 3. According to the velocity field of water, water flow mainly follows the direction with relatively larger gaps between the fixed particles. This indicates that water permeation differs with different locations in the soil-rock mixture. Moreover, water distribution in the axial direction of the soil-rock mixture was investigated at a time of $7.8 \mathrm{~s}$. Three lines at the heights of $\mathrm{Y}=0.0125 \mathrm{~m}, \mathrm{Y}=0 \mathrm{~m}$, and $Y=-0.0125 \mathrm{~m}$ were selected in Fig. 1. As shown in Fig. 4, water distribution along the line of $\mathrm{Y}=0 \mathrm{~m}$ is relatively uniform with a slight decrease along the line. This indicates that water mainly accumulates at this height, since the water jet was set at this height and shows its main influence on water permeation. With the combined action of the gravity and the structure of the soil-rock mixture, water distributions are not uniform respective to the 

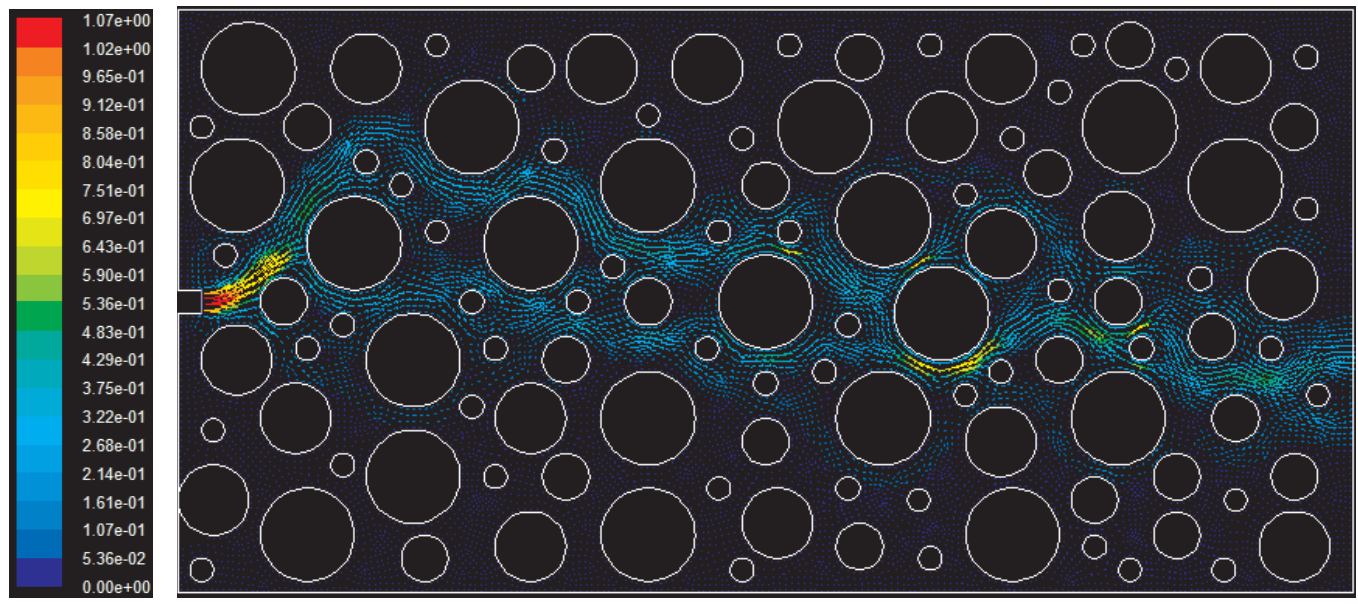

Fig. 3. Velocity field of water.

other lines, which indicates that water permeation in the transverse direction is limited to some extent, and water permeation is not enough in the transverse direction at this time.

Furthermore, water distribution was investigated at different times for some selected point on the line of $\mathrm{Y}=0 \mathrm{~m}$. Five monitoring points are presented in Fig. 1: points 1-5, from left to right. As shown in Fig. 5, there is no water in the soil-rock mixture at $0 \mathrm{~s}$. As water permeates the soil-rock mixture, the volume of water increases sharply for point 1 , which is close to the inlet. Then the volume of water of point 2 increases quickly after point 1 . For point 3 , the volume of water increases quickly at first to some value, then increases slowly, and finally increases quickly to the maximum value, which indicates that water permeation along the soil-rock mixture performs with certain difficulties, which are always accompanied by some blocks, such as the fixed particles. Water permeation is unsteady and the volume of water may increase with fluctuation, such as the volume of water for point 4 . The furthest location of point 5 was not filled with any water.

According to the above analyses, water permeation changes with time and space in the soil-rock mixture.
Water permeability also changes in the soil-rock mixture, which agrees with early relevant findings [47-48]. There are many influencing factors for water permeation of the soil-rock mixture. Major influences of dynamic viscosity, water velocity, size of soil particles, and soil density were considered in the present work.

\section{Influence of Dynamic Viscosity}

With the consideration of the filling soils, the behavior and strength of soil has direct influence on the migration of water through the soil-rock mixture. The dynamic viscosities of different soils were emphasized to see if they influenced water permeability. Soil types ranging from sand to soil with different yield stresses were considered. Sand was assumed as a special phase with low viscosity. The diameter was $100 \mu \mathrm{m}$, and the true density of sand is $2,650 \mathrm{~kg} / \mathrm{m}^{3}$. To have a direct comparison, soil was assumed to be Bingham fluids with a diameter of $100 \mu \mathrm{m}$ and the same true density of sand. The soil can flow when the imposed shear stress is higher than the yield stress. When the imposed shear stress is lower than the yield stress, the soil will perform as solid phase.

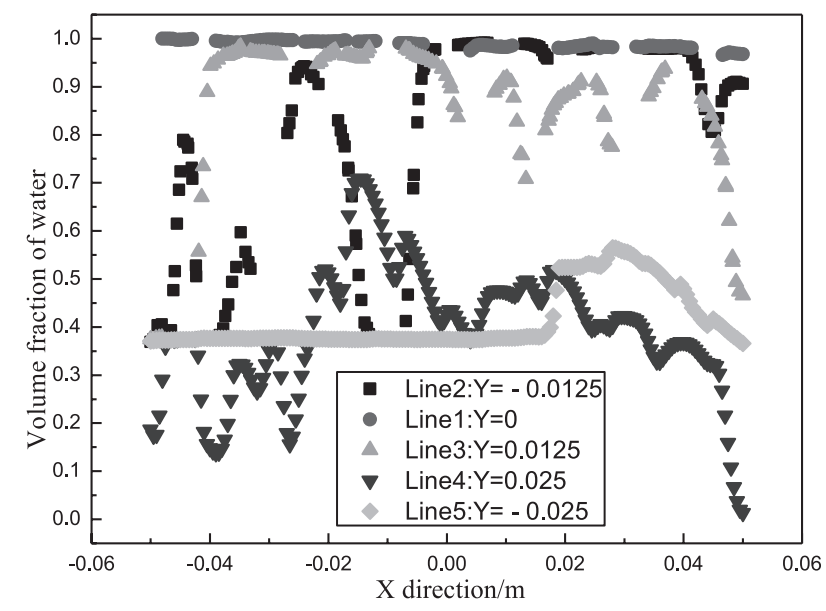

Fig. 4. Water distribution for the monitoring lines.

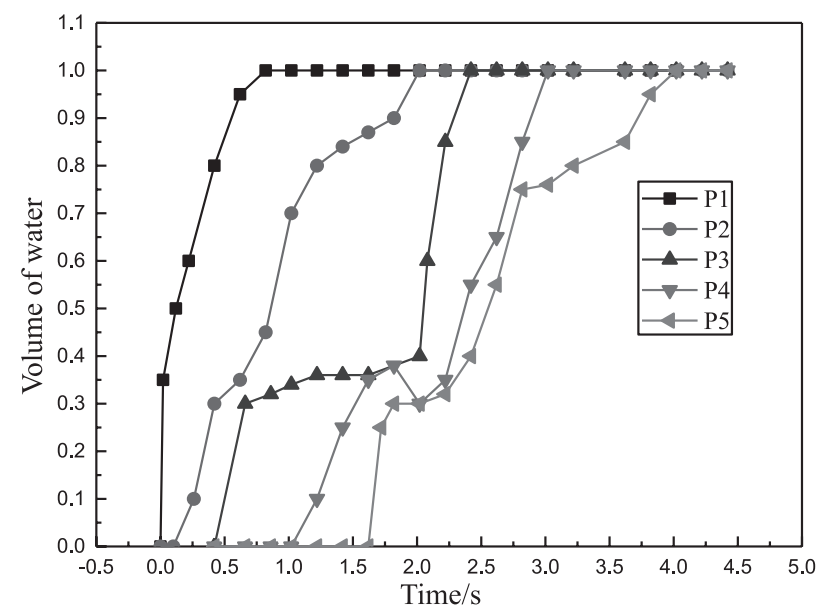

Fig. 5. Water distribution for the monitoring points. 


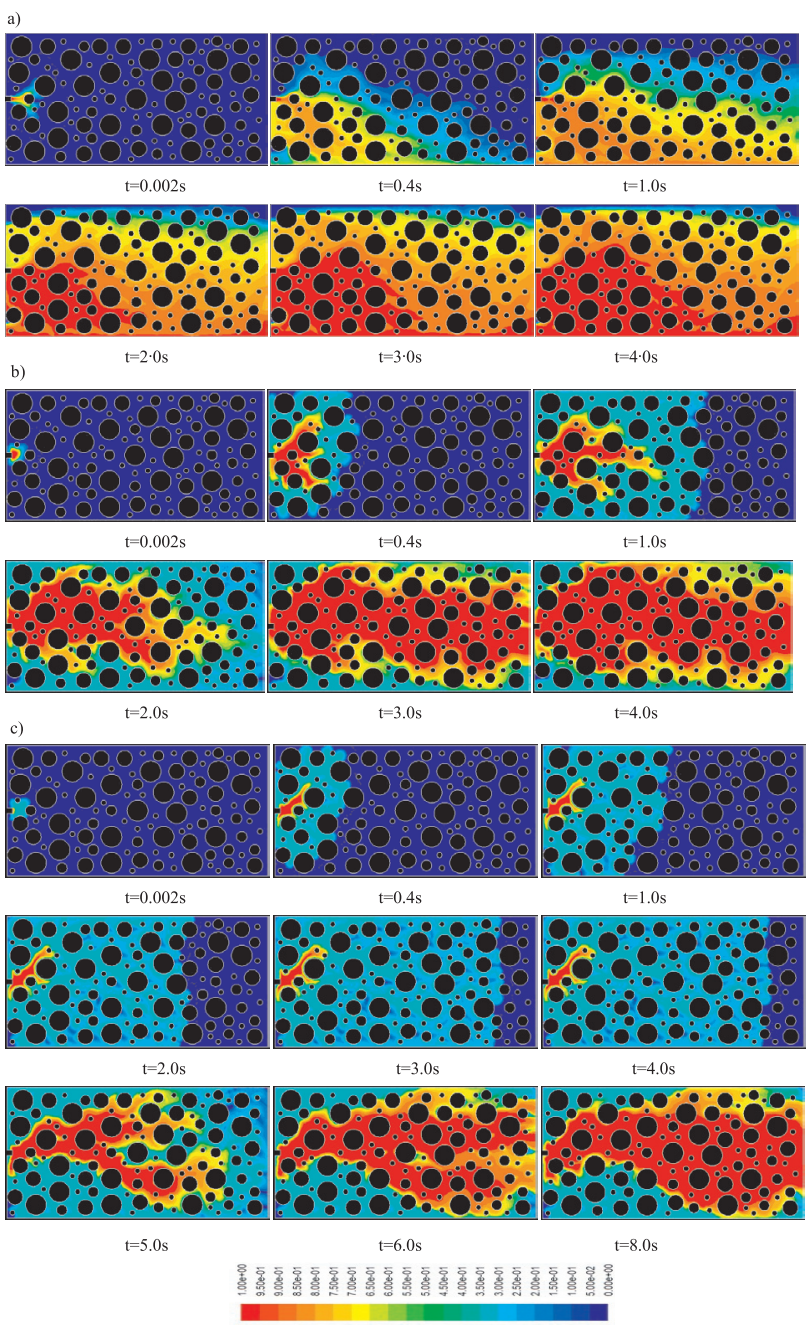

Fig. 6. Water permeation through the soil-rock mixture at various yield stresses of soils: a) simplified sand; b) soil with yield stress of $1 \mathrm{~Pa}$; c) soil with yield stress of $100 \mathrm{~Pa}$.

As shown in Fig. 6a), water was injected into the soilrock mixture filling with sands. There is an obvious jetflow from the inlet. Water flows freely, moves forward, and changes its direction to the bottom due to the fixed particles barrier and gravity. Water moves forward, replaces the sands, and gradually occupies the skeleton from the bottom. For soils with certain yield stress in Fig. 6b), water moves much more slowly through the soil-rock mixture when compared with that of Fig. 6a). The permeability of soil is low, which coincides with the common results (Craig 2013). Water moves slower with larger yield stresses, as shown in Fig. 6c).

The permeation rate of water obviously decreases with the increasing of yield stress. Two times were presented for investigation: the permeation time for water permeating to the outlet, and the penetration time for water flowing out from the outlet. As shown in Fig. 7, the permeation time and the penetration time increase directly with increasing yield stress. When the yield stress of soil is $100 \mathrm{~Pa}$, it takes $3.5 \mathrm{~s}$ for water permeating through the soil-rock mixture. Water flow needs approximately $5.25 \mathrm{~s}$ to reach the outlet,

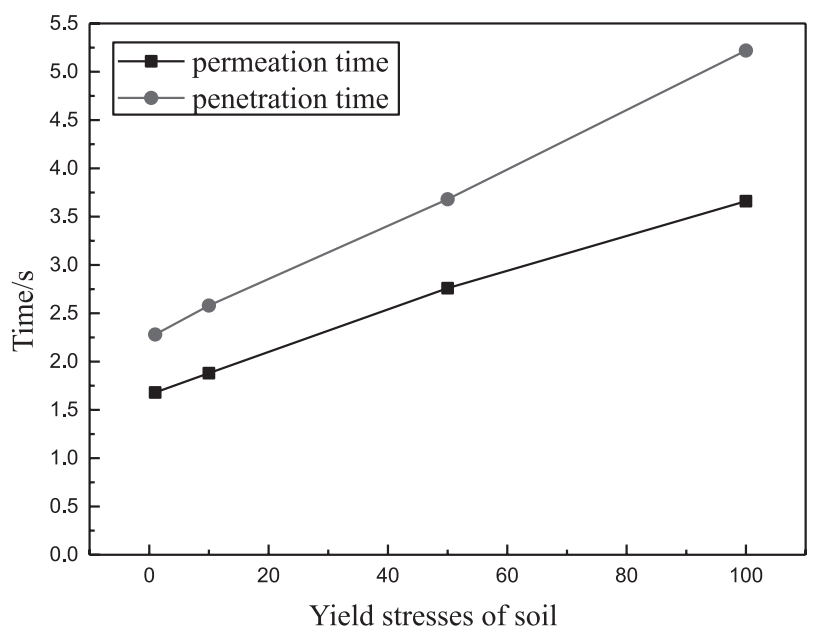

Fig. 7. Times of water permeation through the soil-rock mixture at various yield stresses of soils.

which indicates that the water inflow in the skeleton can be prevented to some extent by the material filled in the skeleton, particularly by soils with a larger yield stress. The results agree with the relative findings of Zhu et al. (2011). Once water occupies the skeleton, it means that the filling material has been removed and the skeleton becomes unstable, which may induce water inrush.

\section{Influence of Water Velocity}

Water velocity was examined to investigate water permeation of the soil-rock mixture. Fig. 8 shows the process of water permeation in the soil-rock mixture at different water velocities. The diameter of soil particles is $100 \mu \mathrm{m}$, and the density of soil is equivalent to the sands.

As shown in Fig. 8, water permeates quickly through the soil-rock mixture, which provides an easy way for water to flow through the skeleton. Then, water will penetrate the soil-rock mixture and flow out from the outlet, and a channel flow of water forms. After that, the channel flow extends in the transverse direction and tends to develop into the plug flow. Water distribution for $5 \mathrm{~m} / \mathrm{s}$ tends to become uniform faster than that of $0.5 \mathrm{~m} / \mathrm{s}$ in Fig. 8a) and $1 \mathrm{~m} / \mathrm{s}$ in Fig. 2. The plug flow is obvious for water velocity of $5 \mathrm{~m} / \mathrm{s}$ at the time of $5 \mathrm{~s}$, while the channel flow of water reaches the out let for water velocity of $0.5 \mathrm{~m} / \mathrm{s}$ at the time of $5 \mathrm{~s}$. In addition, it is faster for water to flow out from the outlet at a water velocity of $5 \mathrm{~m} / \mathrm{s}$. Meanwhile, water permeation in the transverse direction is also faster with high water velocity. In Fig. 8a), water migrates slower for both the transverse direction and the axial direction. Moreover, with the increase of initial water velocity, water permeation becomes uniform more quickly, and the filling soil particles also flow away faster. The trend coincides with the previous relevant results.

The permeation time decreases with the increasing water velocity, as shown in Fig. 9. The penetration time decreases with the increasing of water velocity. The difference between the permeation time and the 


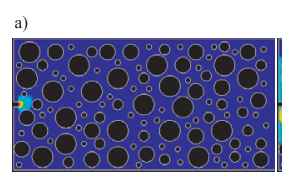

$\mathrm{t}=0.002 \mathrm{~s}$

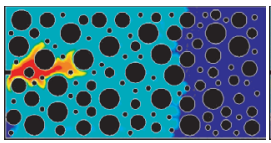

$\mathrm{t}=2.0 \mathrm{~s}$

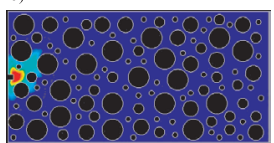

$\mathrm{t}=0.002 \mathrm{~s}$

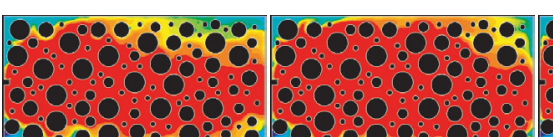

0000 .

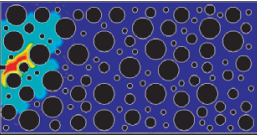

$\mathrm{t}=0.4 \mathrm{~s}$

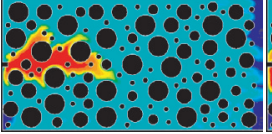

$\mathrm{t}=3.0 \mathrm{~s}$

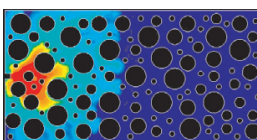

$=0.4 \mathrm{~s}$ $\mathrm{t}=3.0 \mathrm{~s}$

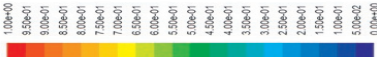

Fig. 8. Water permeation through the soil-rock mixture at various initial water velocities: a) $0.5 \mathrm{~m} / \mathrm{s}$; b) $5 \mathrm{~m} / \mathrm{s}$.

permeation time for one condition also decreases with the increasing of water velocity, which indicates that water permeation and water flow tends to be synchronous under higher water pressure.

The above result indicates that with the increase of the water flow pressure, water permeates through the soil-rock mixture more easily. This shows reasonable agreement with the previous experimental result that the sample will obtain higher values of permeability when the water flow pressure increases, as shown in Fig. 10 [4].

\section{Influence of the Size of Soil Particles}

The behavior and strength of soil is largely determined by the size of its particles [49-50], which also have

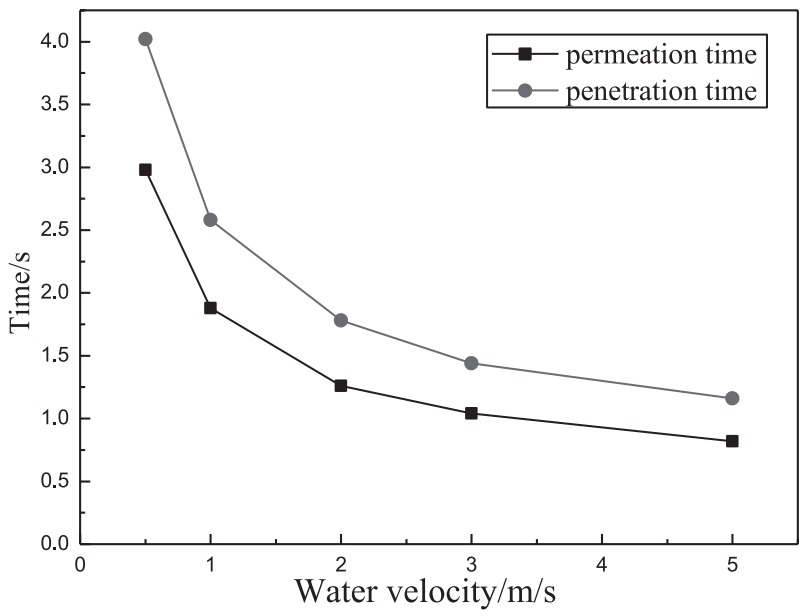

Fig. 9. Times of water permeation through the soil-rock mixture at various initial water velocities.

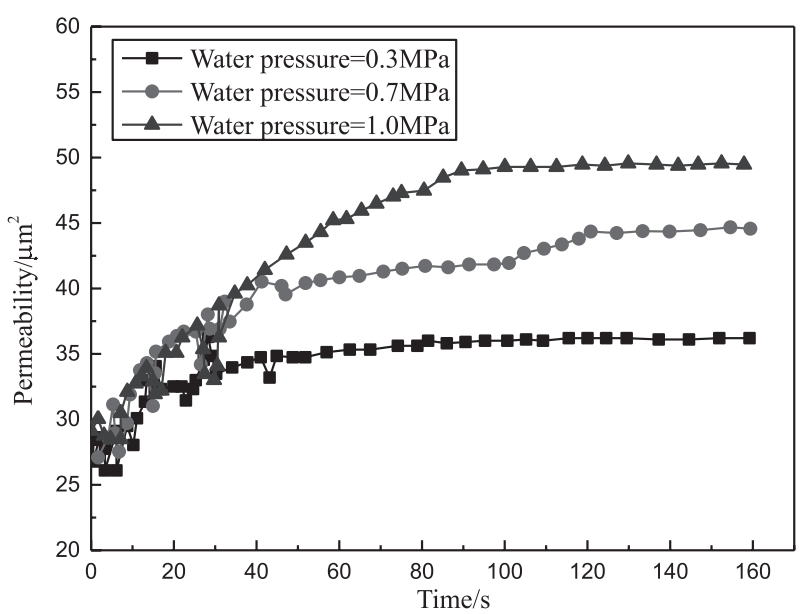

Fig. 10. Variations of permeability with time for samples with the same composition.

obvious influence on water migration through the soilrock mixture. The sizes of soil particles $(100 \mu \mathrm{m}, 10 \mu \mathrm{m}$, $1 \mu \mathrm{m}$, and $0.01 \mu \mathrm{m}$ ) were examined, as shown in Fig. 11. The initial water velocity is $1 \mathrm{~m} / \mathrm{s}$, the true density of soil is the same with the sands.

When the filling particles are finer with a size of $0.01 \mu \mathrm{m}$ in Fig. 11a), the voids between particles are relatively smaller, which possess certain levels of resistance for water permeation. However, the water more easily carries the finer particles, and particle migration is clear within the soil-rock mixture. Thus, water permeation develops quickly. Moreover, water permeation develops almost synchronously with water permeation. When the filling particles are larger with a size of $10 \mu \mathrm{m}$ in Fig. 11b), the voids between particles are relatively larger,

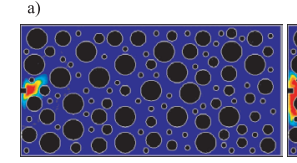

$\mathrm{t}=0.002 \mathrm{~s}$

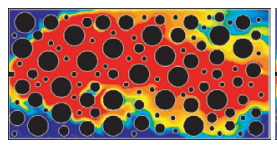

$\mathrm{t}=2.0 \mathrm{~s}$

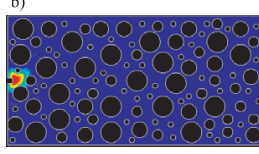

$\mathrm{t}=0.002 \mathrm{~s}$

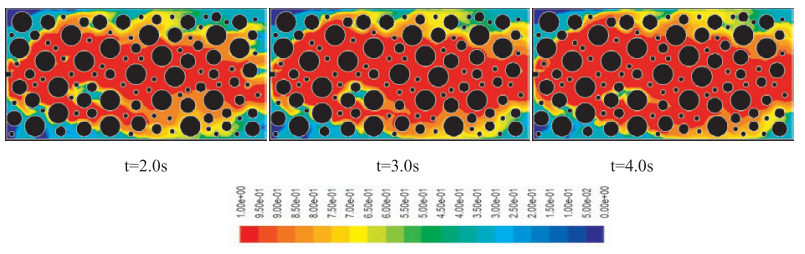

Fig. 11. Water permeation through the soil-rock mixture at various sizes of soil particles: a) $d=0.01 \mu \mathrm{m}$; b) $d=10 \mu \mathrm{m}$. 


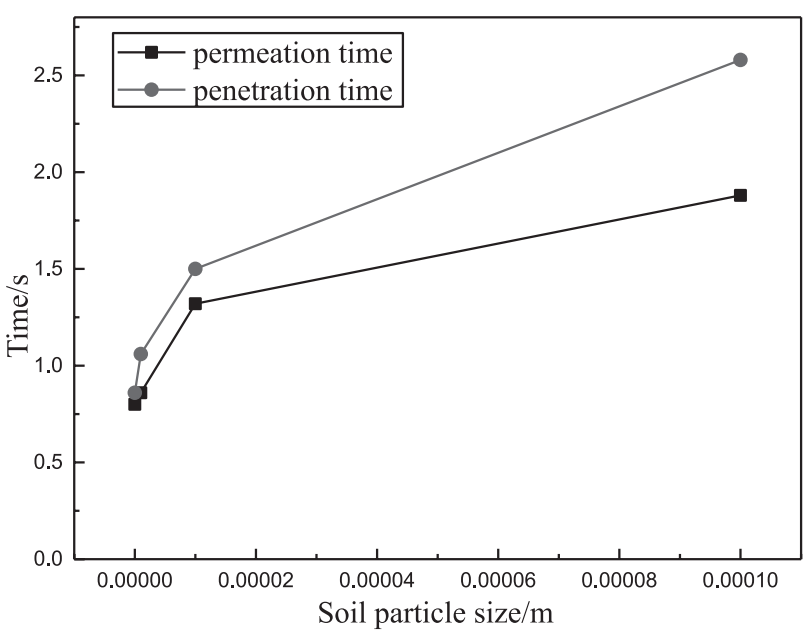

Fig. 12. Times of water permeation through the soil-rock mixture at various sizes of soil particles.

which paves the way for water permeation. Thus water permeation develops more quickly than water penetration. As shown in Fig. 11b), the red area is obviously smaller than that of the light green area. When the filling particles are larger with a size of $100 \mu \mathrm{m}$ in Fig. 2, the voids between particles are clearly larger than the above conditions. Water can permeate the mixture more easily. However, it is more difficult to carry the larger particles away, and particle migration is relatively hard. Thus, the water phase needs more time to remove impediments in its way to permeate. Therefore, water penetration develops far behind water permeation. In a word, the water permeation rate increases with the decrease of particle size. At the same time, the water permeation rate increases obviously with the decrease of particle size. As shown in Fig. 12,

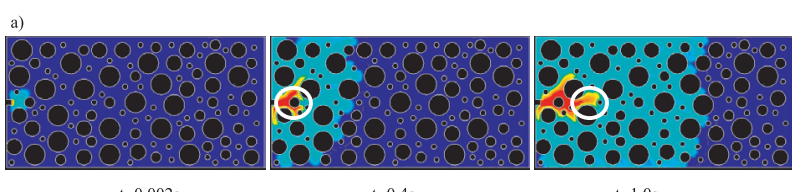

$\mathrm{t}=0.002 \mathrm{~s}$

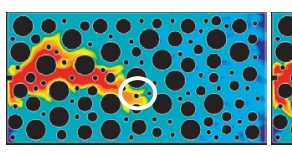

$\mathrm{t}=2.0 \mathrm{~s}$

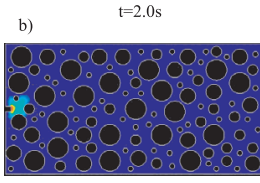

$\mathrm{t}=0.002 \mathrm{~s}$

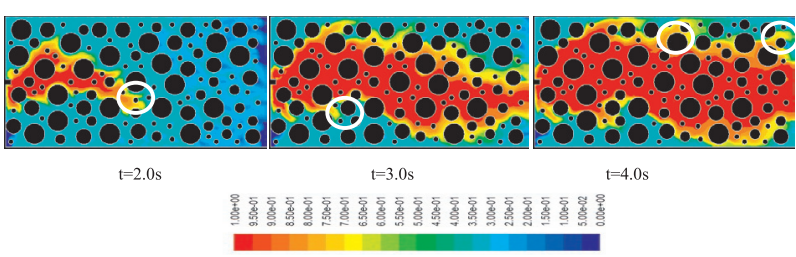

Fig. 13. Water permeation through the soil-rock mixture at various densities of soils: a) $1100 \mathrm{~kg} / \mathrm{m}^{3}$; b) $1600 \mathrm{~kg} / \mathrm{m}^{3}$. the permeation time and the penetration time all increase with the increase of particle size. The difference between permeation time and penetration time for one condition also increases with the increase of particle size. This indicates that filling soil with larger particles can prevent water inflow in the skeleton to some extent.

Generally, water permeation through the soilrock mixture is easier when the filling soil consists of smaller particles. The result shows agreement with the experimental finding that the sample with a higher percentage of small particles reaches higher permeability on the completion of the test [4]. Moreover, the effect of all factors influencing hydraulic property variations can be summed up in the migration of small particles. Therefore, the size of soil particles directly determines the hydraulic properties of granular material, including permeability and porosity [4].

\section{Influence of Soil Density}

Soil density was examined to investigate water permeation of the soil-rock mixture, as shown in Fig. 13. The diameter of soil particles is $100 \mu \mathrm{m}$, the initial water velocity is $1 \mathrm{~m} / \mathrm{s}$, and the true density of soil is equivalent to the sands.

As shown in Fig. 13, the shapes of the permeation areas (the light green area) look the same under different soil densities. The permeation rates seem synchronously under different soil densities. When the dynamic viscosity is fixed, the effect of soil density on water permeation through the soil-rock mixture is not obvious. However, the penetration rate (the red area) with the soil density of 1,100 $\mathrm{kg} / \mathrm{m}^{3}$ is a little slower than that of $1,600 \mathrm{~kg} / \mathrm{m}^{3}$, which can be seen from the white marks. After comparison, the penetration rate with the soil density of $1,600 \mathrm{~kg} / \mathrm{m}^{3}$ is also slower than that of $2,650 \mathrm{~kg} / \mathrm{m}^{3}$ in Fig. 2. This might be due to the viscous effect playing a dominant role in water permeation or soil density, or that gravity shows weak action on water permeation. In other words, the differences of water penetration rates under different soil densities are minimal.

\section{Conclusions}

To further understand the mechanism of water inrush, water permeation through the soil-rock mixture was investigated numerically. The Euler-Euler model was adopted with the consideration of a three-phase system of water, soil, and air. The dynamic viscosities of different filling materials were emphasized based on the dynamic viscosities with additional user-defined functions. The obtained results could present the detailed process of water permeation through the soil-rock mixture, including water permeation, water penetration, and water flow.

Moreover, the major influences of dynamic viscosity of soil, water velocity, size of soil particles, and soil density were considered for water permeation. We found that sand and soil behave differently when water permeates 
through the soil-rock mixture. The yield stress of soil, water velocity, and size of soil particles have clearly influenced the permeation rate of water. The mixture will obtain higher values of permeability when water velocity increases. When the particle size of the filling soil is small, there is a higher potential for particle discharge, and hence a rapid permeability. The particle size of the filling soil has an essential effect on permeability during water permeation through the soil-rock mixture. The influence of soil density on water permeation of the soilrock mixture is not clear. Meanwhile, the permeation time and the penetration time all behave normally with the changing of the main influencing factors.

The present work on water permeation through the soilrock mixture is still in its initial stage. It remains necessary to verify the above method and the results by experiments. Further research on water inrush should be systematically investigated, including improved simulation models, computational ability, experimental measurement, and a new way to address soil-rock mixture and water inrush in underground engineering.

\section{Nomenclature}

$C_{D}$ interphase drag coefficient

$C_{D S P}$ interphase drag coefficient of equivalent spheres

$C_{V}$ added-mass coefficient

$C$ dynamic viscosity coefficient

$\stackrel{\mu}{D}$ mass diffusion coefficient $\left(\mathrm{m}^{2} / \mathrm{s}\right)$

$\overline{\bar{D}}$ the rate-of-deformation tensor

$d$ diameter of the solid phase particles(m)

$F$ force $(\mathrm{N})$

$K$ interphase momentum exchange coefficient

$m_{p q}$ mass flow rate $(\mathrm{kg} / \mathrm{s})$

$R e^{p q}$ Reynolds number

v

$U$ phase-weighted velocity $(\mathrm{m} / \mathrm{s})$

$V$ volume $\left(\mathrm{m}^{3}\right)$

$\stackrel{v}{v}$ overall velocity vector $(\mathrm{m} / \mathrm{s})$

\section{Greek Letters}

$\alpha$ volume fractions

$\beta$ correction coefficient

$\varepsilon$ turbulent dissipation rate $\left(\mathrm{m}^{2} / \mathrm{s}^{3}\right)$

$\eta$ effectiveness factor

$\eta_{p}$ non-Newtonian viscosity

$\theta$ angle between mean particle velocity and mean relative velocity (rad)

$\lambda$ bulk viscosity $(\mathrm{kg} / \mathrm{s})$

$\mu$ dynamic viscosity $(\mathrm{kg} / \mathrm{s})$

$\rho$ physical density $\left(\mathrm{kg} / \mathrm{m}^{3}\right)$

$\sigma$ dispersion Prandtl number

$=$

$\tau$ stress-strain tensor $(\mathrm{Pa})$

$\tau$ time scale(s)

$\overline{\overline{\tau_{0}}}$ yield stress
Subscripts

$c$ continuum phase

$l$ fluid phase

$p$ particle phase

$s$ solid phase

\section{Acknowledgements}

Financial support from the Fundamental Research Funds for the Central Universities (2017XKQY074) is sincerely acknowledged.

\section{References}

1. ZHANG J., PENG S. Water inrush and environmental impact of shallow seam mining [J]. Environ Geol, 48, 2005.

2. LI S.C., ZHOU Z.Q., LI L.P., XU Z.H., ZHANG Q.Q., SHI S.S. Risk assessment of water inrush in karst tunnels based on attribute synthetic evaluation system [J]. Tunn Undergr Sp Tech, 38, 2013.

3. LI L.P., LEI T., LI S.C., ZHANG Q.Q., XU Z.H., SHI S.S. Risk assessment of water inrush in karst tunnels and software development [J]. Arabian J Geo, 8, 2014.

4. MA D., REZANIA M., YU H.S., BAI H.B. Variations of hydraulic properties of granular sandstones during water inrush: effect of small particle migration [J]. Eng Geol, 217, 2016.

5. BAI H.B., MA D., CHEN Z.Q. Mechanical behavior of groundwater seepage in karst collapse pillars [J]. Eng Geol, 164, 2013.

6. WANG J.A., PARK H.D. Fluid permeability of sedimentary rocks in a complete stress-strain process $[\mathrm{J}]$. Eng Geol, 63, 2002.

7. MIAO X.X., LI S.C., CHEN Z.Q. Bifurcation and catastrophe of seepage flow system in broken rock [J]. Min Sci Tech, 19, 2009.

8. WANG J.A., PARK H.D. Coal mining above a confined aquifer [J]. Int J Rock Mech Min Sci, 40, 2003.

9. ZHANG H.Q., HE Y.N., TANG C.A., AHMAD B., HAN L.J. Application of an improved flow-stress-damage model to the criticality assessment of water inrush in a mine, a case study [J]. Rock Mech Rock Eng, 42, 2009.

10. LI L.P., TU W.F., SHI S.S., CHEN J.X., ZHANG Y.H. Mechanism of water inrush in tunnel construction in karst area [J], Geomatics, Natural Hazards and Risk, 7, 2016.

11. LI L.P., ZHOU Z.Q., LI S.C., XUE Y.G., XU Z.H., SHI S.S. An Attribute Synthetic Evaluation System for Risk Assessment of Floor Water Inrush in Coal Mines [J], Mine Water Environ, 34, 2015.

12. LI L.P., LEI T., LI S.C., XU Z.H., XUE Y.G., SHI S.S. Dynamic risk assessment of water inrush in tunnelling and software development [J]. Geomech Eng, 9, 2015.

13. WANG Y.C., YIN X., JING H.W., LIU R.C., SU H.J. A novel model of the cloud for risk analysis of water inrush in karst tunnels. ENVIRON EARTH SCI, 75, 2016.

14. WANG Y.C., JING H.W., YU L.Y., SU H.J., LUO N. Set pair analysis for risk assessment of water inrush in karst tunnels[J]. B ENG GEOL ENVIRON, 7, 2016.

15. WANG Y.C., JING H.W., HAN L.J., YU L.Y., ZHANG Q. Risk analysis on swell -shrink capacity of expansive soils 
with efficacy coefficient method and entropy coefficient method[J]. APPL CLAY SCI, 99, 2014.

16. WANG Y.C., JING H.W., ZHANG Q., LUO N., YIN X. Prediction of Collapse Scope of Deep-Buried Tunnels Using Pressure Arch Theory[J]. Math Probl Eng, 3-4, 2016.

17. WANG Y.C., JING H.W., SU H.J., XIE J.Y. Effect of a Fault Fracture Zone on the Stability of Tunnel-Surrounding Rock[J]. INT J GEOMECH, 17, 2017.

18. WANG Y.C., ZHAO N., JING H.W., Meng B., Yin X. A novel model of the ideal point method coupled with objective and subjective weighting method for evaluation of surrounding rock stability[J]. Math Probl Eng, 12, 2016.

19. VALIPOUR M., BANIHABIB M.E., BEHBAHANI S.M.R. Comparison of the ARMA, ARIMA, and the autoregressive artificial neural network models in forecasting the monthly inflow of Dez dam reservoir [J], J Hydrol, 476, 2013.

20. VALIPOUR M. Variations of land use and irrigation for next decades under different scenarios $[\mathrm{J}]$, Journal of Irrigation and Drainage Engineering, 1, 2016.

21. REZAEI M., VALIPOUR M. Modelling Evapotranspiration to Increase the Accuracy of the Estimat ions Based on the Climat ic Parameters [J], Water Conservation Science \& Engineering, 1, 2016.

22. VALIPOUR M. How Much Meteorological Information Is Necessary to Achieve Reliable Accuracy for Rainfall Estimations [J], Agriculture, 6, 2016.

23. ZHU W.C., WEI C.H. Numerical simulation on mininginduced water inrushes related to geologic structures using a damage-based hydromechanical model [J]. Environ Earth Sci, 62, 2011.

24. CAINE J.S., EVANS J.P., FOSTER C.B. Fault zone architecture and permeability structure $[\mathrm{J}]$. Geol, 24, 1996.

25. ZHANG B.Y., BAI H.B., ZHANG K. Seepage characteristics of collapse column fillings [J]. Int J Min Sci Technol, 26, 2016.

26. MIAO X.X., CUI X.M., WANG J.A., XU J.L. The height of fractured water-conducting zone in undermined rock strata [J]. Eng Geol, 120, 2011 a.

27. MIAO X.X., LI S.C., CHEN Z.Q., LIU W.Q. Experimental study of seepage properties of broken sandstone under different porosities [J]. Transp Porous Media, 86, 2011b.

28. FAUCHILLE A.L., HEDAN S., VALLE V., PRET D., CABRERA J., COSENZA P. Multi-scale study on the deformation and fracture evolution of clay rock sample subjected to desiccation [J]. Appl Clay Sci, 132-133, 2016.

29. XU W.J., HU L.M., GAO W. Random generation of the meso-structure of a soil-rock mixture and its application in the study of the mechanical behavior in a landslide dam [J]. Int J Rock Mech Min Sci, 86, 2016.

30. XU W.J., WANG S., ZHANG H.Y., ZHANG Z.L. Discrete element modelling of a soil-rock mixture used in an embankment dam [J]. Int J Rock Mech Min Sci, 86, 2016.

31. GONG J., LIU J. Analysis on the mechanical behaviors of soil-rock mixtures using discrete element method [J]. Procedia Eng, 102, 2015.

32. LI C.S., ZHANG D., DU S.S., SHI B. Computed tomography based numerical simulation for triaxial test of soil-rock mixture [J]. Comp Geotech, 73, 2015.
33. PERAZZELLI P., LEONE T., ANAGNOSTOU G. Tunnel face stability under seepage flow conditions [J]. Tunn Undergr Sp Tech, 43, 2014.

34. LI S.C., LIU H.L., LI L.P., ZHANG Q.Q., WANG K. Large scale three-dimensional seepage analysis model test and numerical simulation research on undersea tunnel [J]. Appl Ocean Res, 59, 2016.

35. YAO B.H., BAI H.B., ZHANG B. Numerical simulation on the risk of roof water inrush in wuyang coal mine [J]. Int $\mathrm{J}$ Rock Mech Min Sci, 22, 2012

36. VALLEJO L.E. The behavior of granular materials containing large particles, laboratory and finite element analysis. In [C], Proceedings of the 5th European conference on numerical methods in geotechnical engineering, Paris; 39, 2002.

37. YUE Z.Q., CHEN S., THAM L.G. Finite element modeling of geomaterials using digital image processing $[\mathrm{J}]$. Comput Geotech, 30, 2003.

38. CHEN S., YUE Z.Q., THAM L.G. Digital image-based numerical modeling method for prediction of inhomogeneous rock failure [J]. Int J Rock Mech Min Sci, 41, 2004.

39. LI Y., ZHANG D., FANG Q., YU Q., XIA L. A physical and numerical investigation of the failure mechanism of weak rocks surrounding tunnels $[\mathrm{J}]$. Comput Geotech, 61, 2014.

40. XU H., ZHU W., QIAN X., WANG S., FAN X. Studies on hydraulic conductivity and compressibility of backfills for soil-bentonite cutoff walls [J]. Appl Clay Sci, 132-133, 2016.

41. WACHEM B.G.M., ALMSTEDT A.E. Methods for multiphase computational fluid dynamics $[\mathrm{J}]$. Chem Eng J, 96, 2003.

42. GENG F., XU D., YUAN Z., YAN Y., LUO D., WANG $\mathrm{H}$. Numerical simulation on fluidization characteristics of tobacco particles in fluidized bed dryers [J]. Chem Eng J, 150, 2009

43. WANG Y.C., LUO G., GENG F., LI Y.L., LI Y.B. Numerical study on dust movement and dust distribution for hybrid ventilation system in a laneway of coal mine [J]. J Loss Prevent Proc Ind, 36, 2015.

44. Fluent, Inc., FLUENT User Defined Function Manual, Fluent Inc., 2006.

45. ANSYS Fluent theory guide. Release 13. ANSYS, Inc, 2010

46. AHMADPOUR A., SADEGHY K. Swirling flow of bingham fluids above a rotating disk, an exact solution [J]. J Non-Newtonian Fluid Mech, 197, 2013.

47. ZHU H., MARTYS N.S., FERRARIS C., KEE D.D. A numerical study of the flow of bingham-like fluids in twodimensional vane and cylinder rheometers using a smoothed particle hydrodynamics (sph) based method [J]. J NonNewtonian Fluid Mech, 165, 2010.

48. ZHU B., WU Q., YANG J., CUI T. Study of pore pressure change during mining and its application on water inrush prevention, a numerical simulation case in zhaogezhuang coalmine, china [J]. Environ Earth Sci, 71, 2013.

49. FIĖS J.C., BRUAND A. Particle packing and organization of the textural porosity in clay-silt-sand mixtures $[\mathrm{J}]$. Eur $\mathrm{J}$ Soil Sci, 49, 1998.

50. CRAIG R.F., KNAPPETT J.A. Craig's Soil Mechanics $\left(8^{\text {th }}\right.$ edition) [M]. Springer, London, United Kingdom, 2013. 